\title{
Association between history of abdominopelvic surgery and tubal pathology
}

\author{
*Famurewa $\mathrm{O}^{1}$, Adeyemi $\mathrm{A}^{2}$, Ibitoye $\mathrm{O}^{1}$, Ogunsemoyin $\mathrm{O}^{3}$
}

1. Department of Radiology, Obafemi Awolowo University and Obafemi Awolowo University Teaching Hospital, Nigeria

2. Department of Obstetrics \& Gynaecology, Obafemi Awolowo University, Nigeria

3. Department of Radiology, Obafemi Awolowo University Teaching Hospital, Nigeria

\begin{abstract}
Background: Pelvic infection, unsafe abortion and previous laparatomy are risk factors for tubal infertility among Nigerian women. Reports on the relationship between these factors and tubal pathology seen on hysterosalpingography (HSG) from our environment have been few.

Objective: To assess the prevalence of tubal occlusions among patients referred for HSG and examine the association between previous history of abdominopelvic surgery (including dilatation and curettage for abortion) and tubal occlusion. Methods: We studied one hundred and thirty women referred to the Radiology department for HSG because of infertility. HSG was performed during the early proliferative phase of the menstrual cycle. Information about type and duration of infertility, history of abdomino -pelvic surgery and history suggestive of previous pelvic infection, were obtained from the patients. The data obtained were analyzed using SPSS version 11. Test of association using the chi-square test was done where appropriate and differences were considered at $\mathrm{p}=0.05$.

Results: Sixty one women had bilaterally patent tubes; tubal pathology was seen in sixty nine women. Significant association exits between tubal pathology and history of pelvic surgery $\mathrm{p}=0.01$, pelvic infection $\mathrm{p}=0.02$ and duration of infertility $\mathrm{p}=0.04$.

Conclusion: Previous surgery especially dilation and curettage, PID duration and type of infertility are associated with tubal pathology among Nigerian women. Creative methods of lowering the cost of diagnosis and management of tubal occlusion need to be instituted.
\end{abstract}

African Health Sciences 2013; 13(2): 441 - 446 http:/ /dx.doi.org/10.4314/ahs.v13i2.34

\section{Introduction}

The tubal factor is reported to account for $20-35 \%$ of subfertility in the Western medical literature ${ }^{1}$. It has also been identified as the commonest HSG finding in infertile Nigerian women and commonest cause of infertility in Africa and in Nigeria ${ }^{2}$. Tubal occlusion is the commonest HSG finding in infertile Nigerian women. Pelvic infection and previous laparatomy are recognized risk factors for the development of tubal subfertility ${ }^{3}$.

Infective tubal damage can be caused by sexually transmitted diseases or can occur after miscarriage, termination of pregnancy or pueperal sepsis. The ascending infection which is usually caused by Chlamydia trachomatis or by Neisseria gonorrhoea may lead to tubal mucosal damage, tubal

\begin{tabular}{|l|}
\hline *Corresponding author: \\
Olusola Famurewa \\
Department of Radiology \\
Obafemi Awolowo University Teaching Hospital \\
Nigeria \\
Email: amurede@gmail.com \\
\hline
\end{tabular}

African Health Sciences Vol 13 Issue 2 June 2013 fibrosis and occlusion which may be unilateral or bilateral and can affect any part of the tube.

The association between infection and tubal disease among Nigerian women is well documented 2,5. Okonofua ${ }^{6}$ in 1994 carried out a questionnaire based study to ascertain the impact of induced and unsafe abortion as a cause of infertility among women in Ile Ife and concluded that induced abortion was associated with infertility although they did not examine their patients to confirm the contribution of tubal factor to infertility in their study population. Adhesions are an inevitable consequence of intra-abdominal or pelvic surgery, arising following more than $50 \%$ of all abdominal operations. They attach normally separated organs to each other giving rise to small bowel obstruction, dyspareunia, chronic pelvic pain and (adhesions) are also responsible for $15 \%$ to $20 \%$ of all cases of secondary infertility ${ }^{4}$. Para-ovarian and peri-tubal adhesions can lead to follicular entrapment, reduced motility and mechanical blockage of the fallopian 
tubes thereby limiting oocyte transport and increasing the risk of ectopic pregnancy.

HSG is a simple safe and cost effective radiographic study of the uterine cavity and the fallopian tubewith $65 \%$ sensitivity and $83 \%$ specificity for detecting tubal blockage ${ }^{3}$. This implies that $35 \%$ of tubal occlusion remains undetected and $17 \%$ of tubal occlusion on HSG is a false positive result. Laparoscopy with dye test is the procedure of choice in the patient with abnormal HSG for further confirmation and assessment. It will reveal additional causes of infertility such as endometriosis and pelvic adhesion and where the resources are available it also offers the option of performing laparoscopic surgery.

In this study we aimed at determining the prevalence of tubal occlusion among patients referred for HSG in our hospital. We also aimed at finding out the association between tubal occlusion, and the history of previous surgery, namely abdominal and pelvic surgeries including surgically induced abortion among Nigerian women with infertility.

\section{Methods}

The study was conducted in Obafemi Awolowo Teaching Hospital; Ile-Ife.

We studied one hundred and thirty (130) women who were referred to the Radiology department for HSG because of infertility.

HSG was performed by the radiologist during the early proliferative phase of the menstrual cycle. As part of the pre procedure interview, information about type and duration of infertility, history of abdomino -pelvic including surgically induced abortion and history suggestive of previous pelvic infection, as well as demographic details were obtained from the patients by the radiologist. The patients whose studies were considered technically suboptimal were excluded from the study.

Tubal obstruction was diagnosed on HSG if there is either of the following;

(1) failure to totally opacify the tubes from cornu to the fimbria ends with contrast, even after administration of a spasmolytic agent in cases of suspected tubal spasm (proximal obstruction),

(2) tubal dilatation with prolonged retention of contrast medium and no spillage of contrast into the peritoneum (distal obstruction or hydrosalpinx). We defined tubal pathology as proximal or distal obstruction involving either one or both of the tubes.
The data obtained were analyzed using SPSS version 11.Test of association using the chi-square test was done where appropriate and differences were considered at $\mathrm{p}=0.05$.

\section{Results}

One hundred and thirty (130) women were studied. Their ages ranged from 20 to 49 years, (mean $=23$ years). The commonest age group seen was 30-39 years ( 80 women). The indication for HSG was primary infertility in thirty four women (34) and secondary infertility in ninety six women (96). The duration of infertility ranged from one to twenty seven (27) years with a mean of 4.7 years. Eighty nine (89) of the women had previous pelvic surgery at least once; of these seventy seven (77) had dilation and curettage at least once (72) for termination of pregnancy and 5 as part of treatment for spontaneous incomplete abortion).1. Eighty six (86) of the women gave history suggestive of previous pelvic infection.

Reports of HSG findings revealed that sixty one $(46.9 \%)$ of the women had bilaterally patent tubes, tubal occlusion was seen in sixty nine $(53.1 \%)$ women, of these thirty three $(25.4 \%)$ had hydrosalpinges. The women with tubal occlusion were not significantly older (mean $=34.1, \mathrm{SD}=5.19)$ than those with bilaterally patent tubes (mean 32.6, $\mathrm{SD}=4.98) \mathrm{p}=0.097$. Duration of infertility was significantly longer in women with tubal occlusion $\mathrm{p}=0.04$. The mean duration and SD in the tubal occlusion group was 5.4 years $(\mathrm{SD}=4.9)$ compared with women with bilaterally patent tubes 3.8 years $(\mathrm{SD}=3.2)$.

A significant association exists between tubal occlusion and the type of infertility (primary or secondary) with $\mathrm{p}$ value of 0.005 .

Our data showed a significant association between tubal occlusion and history of pelvic surgery irrespective of whether the patient has had single or multiple surgeries, $p=0.01$. We also found an association between incidence of tubal occlusion and previous history of pelvic infection $(\mathrm{p}=0.02)$. 
Table 1: Past medical history versus tubal occlusion

\begin{tabular}{llll}
\hline Past medical history & Tubal occlusion & No tubal occlusion & Statistics p value \\
\hline & $\mathbf{n}(\%)$ & $\mathbf{n}(\%)$ & \\
Surgery $(\mathrm{n}=89)$ & $54(60.5)$ & $34(39.5)$ & 0.02 \\
D AND C $(\mathrm{n}=77)$ & $48(62.3)$ & $29(37.7)$ & 0.01 \\
Infection $(\mathrm{n}=86)$ & $52(60.5)$ & $34(39.5)$ & 0.005 \\
Primary infertility $(\mathrm{n}=29)$ & $9(31)$ & $20(69)$ & 0.005 \\
Secondary infertility $(\mathrm{n}=75)$ & $44(58.7)$ & $31(41.3)$ & \\
\hline
\end{tabular}

\section{Discussion}

Tubal occlusion is the commonest HSG finding in infertile Nigerian women and is the commonest cause of infertility seen in gynaecological clinics in Nigeria. HSG is a simple safe and cost effective radiographic study of the uterine cavity and the fallopian tube with $65 \%$ sensitivity and $83 \%$ specificity for detecting tubal blockage ${ }^{3}$. This implies that $35 \%$ of tubal occlusion remains undetected and $17 \%$ of tubal occlusion on HSG is a false positive result. Laparoscopy, with dye test, although not used in this study, is the procedure of choice in the patient with abnormal HSG for further confirmation and assessment.

Proximal occlusion of tubes seen on HSG is often due to tubal spasm which may not occur under general anaesthesia during laparoscopy. Furthermore laparoscopy will reveal additional causes of infertility such as endometriosis and pelvic adhesion and where the resources are available it also offers the option of performing laparoscopic surgery. Though there have been reports of gynaecologic laparoscopy in Nigeria since the eighties, availability of this modality in Nigerian hospitals has been inconsistent and few studies have reported the use of laparoscopy for diagnostic purposes $^{7,8}$. Other methods of tubal assessment include retrograde tubal cannulation during HSG or laparoscopy. Direct visualization of the tubal lumen by tubal catheterization via laparoscopy, hysteroscopy, or transcervically can also be done as an outpatient procedure (falloposcopy) ${ }^{9}$. Sonohysterography can also be used to evaluate tubal patency and it also allows evaluation of the uterine cavity. It is less invasive, cheaper and has no radiation exposure compared with conventional $\mathrm{HSG}^{3}$.

Tubal occlusion was seen in $51.1 \%$ of our patient population. This agrees with other studies that tubal occlusion is the commonest cause of infertility in Nigeria. Management of tubal occlusion includes hydrotubation, adhesiolysis, tubal macro or micro surgery and In Vitro Fertilization (IVF). In Nigeria facilities for tubal surgery are not freely available; in addition there are less than 10 well accredited IVF centres in the country mostly in the private sector. Despite the fact that the first IVF centre in Nigeria was established in the eighties ${ }^{10}$ the cost is still prohibitive. A single IVF treatment costs around US $\$ 2500$ but the minimum wage is just US $\$ 52.60$ a month, therefore the average person cannot afford this option ${ }^{11}$. However Orhue et al recommended that treating the patients in batches may lower the cost of IVF for the individual patient ${ }^{12}$.

Our data showed a significant association between previous history of abdominal or pelvic surgery and the occurrence of tubal pathology in the population we studied. The commonest surgical procedure among these women was dilation and curettage either for termination of pregnancy or as part of treatment for spontaneous abortion. Majority $(62.3 \%)$ of the women who have had D and $\mathrm{C}$ had tubal pathology. This finding is similar to that of a study of 6149 couples in the Netherlands ${ }^{12}$ which revealed that a history of induced abortion is associated with an increased risk of tubal pathology. An earlier study from the Netherlands ${ }^{13}$ and two others from Mexico ${ }^{14}$ and Vietnam ${ }^{15}$ respectively did not identify induced abortion as a risk factor for tubal infertility. However, several studies from Nigeria have demonstrated an association between infertility and induced abortion; two of these specifically identified the consequences of unsafe abortion as a major factor in tubal infertility. The unanimity of the Nigerian studies including ours may be explained by the fact that the level of unsafe abortion is high among Nigerian women. Abortion law is restrictive in Nigeria; therefore abortion is mostly performed clandestinely and often results in complications such as post-abortal sepsis which may lead to tubal damage and peritubal adhesions ${ }^{16,17}$.

Ten of the women we studied have had previous caesarean section (CS); two of them have 
tubal pathology. Though the number of women with previous exposure to CS in our study is too small for independent statistical analysis, previous studies have shown that CS does not appear to be significantly associated with tubal infertility ${ }^{18}$. Following a case controlled study Saraswat et al suggested that perhaps the presumed role of potential pelvic infection, scarring and adhesion after $\mathrm{CS}$ as a cause of subsequent tubal damage may need to be reconsidered. It is instructive to note that the two women with previous CS and tubal pathology also had a previous history of $\mathrm{D}$ and $\mathrm{C}$, only one other woman in this group has had D and C but she has bilaterally patent tubes. Prophylaxis and or early diagnosis of infection and treatment in women with caesarean deliveries could limit the course and severity of infection and thus decrease the severity of tubal damage. In addition when considering adhesion as a complication of CS it is important to note that the gravid uterus is larger and more vascular than a non-gravid uterus and that the process of healing after a CS maybe different from that following myomectomy or other types of gynaecological surgery ${ }^{19}$.

Tubal pathology was found in all the women who have had upper abdominal surgery ${ }^{4}$, surgery for ectopic pregnancy ${ }^{3}$ and appendectomy ${ }^{7}$. Of the four women who have had myomectomy, three had tubal pathology. It is globally accepted that adhesions are almost invariable after abdominal surgery. However in women, anatomical blockage can result when adhesion closes the abdominal orifice of the fallopian tubes and functional blockage occurs when adhesion causes the retraction of the ovary and or tube. The subsequent increase in space between the ovary and the orifice of the tube may interfere with oocyte pick up thus leading to infertility.

Eighty three women gave history suggestive of PID and sixty six (52.8\%) of them had tubal pathology. Our results are in agreement with the well documented link between pelvic infection and tubal pathology among Nigerian women ${ }^{2}$, and women in other parts of the world. Pelvic inflammatory disease is caused by an ascending infection from the vagina and cervix. Chlamydia trachomatis is the predominant organism causing PID although newer evidence has shown that aetiology could be polymicrobal. In this study we suspected a previous PID if the women gave a history of vaginal discharge, dyspareunia and chronic pelvic pain. Since we did not carry out any laboratory evaluation for $\mathrm{C}$ trachomatis or $\mathrm{N}$. gonorhea (the two commonest causative agents), it is possible that the incidence of previous PID among our patients was underestimated as it has been shown that even in women with serological evidence of past chlamydial or gonococcal infections most are unaware of the infection.

Age related infertility among women is primarily due to oocyte abnormalities and decreased ovarian reserve. According to a recent study involving 7172 women $^{20}$, older women are more likely to have tubal infertility than younger ones. This is contrary to the findings in our study where there is no significant difference in the mean age of women with tubal pathology and those with bilaterally patent tubes. This is probably due to the relatively small number of women we studied and the confounding effect of previous history of dilation and curettage in our study population. The mean age of 23 years among our patient is lower than what is seen in the western world. This is may be explained by the fact that women marry earlier in our culture. However the implication of this younger age is of potential benefits in terms of the success of super ovulation in IVF because ovarian reserve in women decreases with increasing age ${ }^{20}$.

In this study, longer duration of infertility was significantly associated with tubal pathology. Our finding is similar to that of Farhi et $\mathrm{al}^{21}$ and affirms that there is a negative correlation between duration of infertility and the ability to conceive spontaneously. Therefore, duration of infertility is one of the major factors that should be considered in the management of the sub fertile woman.

Similarly, we found that there is a significant relationship between the type of infertility (primary or secondary) and tubal pathology as shown by an earlier studies ${ }^{22}$. Previous mismanaged pregnancies tend to impact negatively on fertility. Moreover, up to $30 \%$ of pelvic infections among African women are attributable to pregnancy related sepsis ${ }^{23}$.

\section{Conclusion}

In this study we found an association between tubal occlusion and previous history of infection and abdominopelvic surgery especially dilatation and curettage. These causes (infection and D and C for termination of unwanted pregnancy) are preventable causes of infertility. The implication is that strategies of prevention must be in place for the sub group of patients at risk of infertility from these causes. In conclusion, HSG is still remains a crucial and basic tool for investigating infertility in Nigeria but the need 
to compliment the findings with laparoscopy cannot be overemphasized in view of the high contribution of tubal factor to infertility in Nigeria. Campaign against unwanted pregnancy, promotion of responsible sexual behavior among adolescents with establishment of youth friendly, family clinics and increasing the knowledge of youth about contraception are key to promoting the reproductive health of the people of Nigeria. It is obvious that these preventive approaches are cheaper and more effective than the treatment of tubal occlusion which was present in more than $50 \%$ of our study population. Creative ways of reducing the cost of diagnosis and management need to be explored and instituted in order to solve the problem of infertility in Nigeria.

\section{References}

1. Madhuri Patil. Assessing tubal damage. J Hum Reprod Sci. 2009; 2(1):2-11.

2. Audu BM, Massa AA, Bukar M, El-Nafaty AU, Sa'ad ST. Prevalence of utero-tubal infertility. J Obstet Gynaecol 2009; (4)29: 326-328.

3. Yacoub Khalaf. Tubal subfertility. BMJ 2003;327: 610-613

4. Brüggmann $D$, Tchartchian $G$, Wallwiener $M$, Münstedt K, Tinneberg HR, Hackethal A. Dtsch Arztebl Int. Intra-abdominal adhesions: definition, origin, significance in surgical practice, and treatment options. Dtsch Arztebl Int. 2010;107 (44):769-775.

5. Omo-Aghoja LO, OkonofuaFE, Onomu SO Larsen U, Bergstrom S. Association of C trachomatis serology with tubal infertility in Nigerian women. J Obst Gynaecol Res. 2007;33(5)688-695.

6. Okonofua FE,Akonai KA Digghiloghi MD. Lower genital infection in infertile Nigerian women compared with controls. Genitourin Med. 1995;71(3):163-168.

7. Otolorin EO, Ojengbede $\mathrm{O}$, Falase O.Laparoscopic evaluation of the tuboperitoneal factor in infertile Nigerian women. Int J Gynaecol Obstet 1987;25(1):47-52

8. Efetie ER, Abubakar JS, Habeeb SA. Audit of gynaecological laparoscopies in National Hosital Abuja, Nigeria. Niger J Clin Pract 2009; 12(2):149-52

9. Forti G, Krausz C. Evaluation and treatment of the infertile couple. Journal of clinical endocrinology and metabolism. 1998; 83(12):417688
10. Ogedengbe BK, Giwa-Osagie OF, Emuveyan MB. J Natl Med Assoc 1987 May;79(5):510-12

11. Orhue AA, Aziken ME, OsemwenkhaAP, Ibadin KO,,Odoma G. I nVitro Fertilization at a public hospital in Nigeria. Int J Gynaecol Obstetr, 2012; 118(1):56-60

12. 12.Verhoeve HR, Steures p, Flierman PA, van der Veen F, Mol BW. History of induced abortion and the risk of tubal pathology. Reprod Biomed Online. 2008; 16(2):304-307.

13. Lalos O. Risk factors for infertility among fertile and infertile women. Eur J Obstet Gynecol Reprod Biol. 1988; 29(2):129-136.

14. Torres-Sánchez L, Lopez-Carrillo L, Espinoza $\mathrm{H}$, Langer A. Is induced abortion a contributory factor to tubal infertility in Mexico? Evidence from a case controlled study. BJOG. 2004;111 (11):1254-1260.

15. Minh PN, Vinh NQ, Tuong HM, Danh MT, Lan VT, Trong DM, Hai HT, Quoc NT, Hanh TL, Le Dong K, Goto A. A case controlled study on the relationship between induced abortion and secondary tubal infertility in Vietnam. Fukushima J Med Sci. 2002; 48(1):1525.

16. Umeora OU, Mbazor JO, Okpere EE. Tubal factor infertility in Benin City, Nigeria sociodemographics of patients and aetiopathogenic factors. Trop Doct. 2007; 37(2):92-94.

17. Okonofua FE, Onwudiegwu U, Odunsi OA. Illegal induced abortion: a study of 74 cases in Ile-Ife, Nigeria. Trop Doct. 1992; 22(2):75-78.

18. Saraswat L, Porter M, Bhattacharya S. Caesarian Section and tubal infertility: is there an association? Reprod Biomed Online. 2008;17(2):259-264.

19. Chapa H, Sbarra M. The paucity of information on adhesions after cesarean delivery. Journal of Gynecologic Surgery. 2010; 26(4): 255-260.

20. Maheshwari A, Hamilton M, Bhattacharya S. Effect of female age on the diagnostic categories of infertility. Hum. Reprod. 2008; 23 (3) $538-542$.

21. Farhi J, Homburg R, Ben-Haroush A. Male factor infertility may be associated with a low risk for tubal abnormalities. ReprodBiomed Online. 2011;22(4):335-340.

22. Lash MM, Yaghamee A, Strohsnitter W, Lalwani S. Association between secondary infertility and fallopian tube obstruction on 
hysterosalpingography. $J$ Reprod Med. 2008;53(9):677-680.

23. Ericksen K, Brunette T. Patterns and predictors of infertility among African women, a cross national survey of twenty seven nations. Soc Sci Med. 1996;42:209-220. 